\title{
Amniotic fluid embolism and disseminated intravascular coagulation complicating hypertonic saline-induced abortion
}

\author{
S. BALLAS* \\ M.D. \\ J. B. LESSING* \\ M.D. \\ M. MICHOWITZ $\dagger$
M.D. \\ * Department of Obstetrics and Gynecology, and †Department of Surgery, Tel Aviv Medical Center and \\ Sackler School of Medicine, Tel Aviv University, Tel Aviv, Israel
}

\begin{abstract}
Summary
Amniotic fluid embolism (AFE) associated with disseminated intravascular clotting (DIC) is usually fatal. Such a combination generally occurs at the term of pregnancy or in the immediate postpartum period. A case of AFE with DIC following a hypertonic-salineinduced abortion, is reported. The patient was in the midtrimester with a live fetus. Prompt recognition and treatment of her condition ensured her complete recovery. Such a case has not, to our knowledge, been previously reported.
\end{abstract}

KEY WORDS: amniotic fluid, clotting, abortion, embolism.

\section{Introduction}

Intra-uterine instillation of hypertonic solutions to induce abortion was introduced as a simpler, safer alternative to hysterotomy, when uterine size makes interruption by curettage or vacuum aspiration, dangerous. Hypertonic solutions can be used from the 12 th to the 28 th weeks of pregnancy.

Many complications of this technique have been reported: fever and infection (Gillmer, Friend and Beard, 1971; Goodlin et al., 1969; Mackenzie, Roufa and Tovell, 1971; Stim, 1972), haemorrhage (Stim, 1972), coagulation defects (Beller et al., 1972; Brown, Davidson and Phillips, 1972; Goodlin, 1971; Halbert et al., 1972), hypernatraemia (Cameron and Dayan, 1966; Droegemuller and Greer, 1970; Kerenyi, 1969), water intoxication (Abdul-Karim and Assali, 1961; Goodlin, 1971; Whalley and Pritchard, 1963), transplacental haemorrhage (Jorgenson, 1969; Parmely, Montague and Miller, 1970; Voigt and Britt, 1969), retained placenta (Frigoletto and Pokoly, 1971; Futoran, Lowenstein and Peacock, 1969; Kerenyi, 1971) uterine lacerations (Svane, 1960; Wood, Booth and Pinkerton, 1962), and maternal death (Cameron and Dayan, 1966; Goldman and Eckerling, 1972; Pathak, 1968). Amniotic fluid embolism (AFE) is a further possible complication.

\section{Case report}

A 25-year-old woman, gravida I, para o, was admitted at 20 weeks' gestation, for induction of abortion following a first trimester rubella infection. The haemoglobin was $11.5 \mathrm{~g} / \mathrm{dl}$, the white cell count, platelet count coagulation tests, serum electrolytes, electrocardiogram (ECG) and chest X-ray were normal. At midday $200 \mathrm{ml}$ of amniotic fluid were aspirated and replaced by $200 \mathrm{ml}$ of $20 \%$ saline. Twenty-two hours later, routine coagulation tests and electrolytes were normal. Twenty-six hours after the $20 \%$ saline instillation, uterine contractions and a fetal heart were detectable. Thirty hours following instillation, intravenous oxytocin $(52 \mathrm{mu} . / \mathrm{min})$ was given to increase irregular uterine contractions. The fetal heart was still detectable at this stage. Three hours before she delivered, the patient required analgesia for painful contractions, which were palpable, 4 in $10 \mathrm{~min}$. At $33 \mathrm{hr}$ the membranes ruptured and $45 \mathrm{~min}$ later, a dead fetus weighing $480 \mathrm{~g}$, and complete placenta were delivered. The blood loss was about $100-150 \mathrm{ml}$ and contained clots.

Acute respiratory distress appeared $5 \mathrm{~min}$ after completion of the abortion, followed by apnoea and cyanosis. The patient developed hypotension (systolic pressure $80 \mathrm{mmHg}$ ) and tachycardia $(140 / \mathrm{min})$. Brief generalized convulsions were followed by unconsciousness. The patient was intubated and ventilated with $100 \%$ oxygen. Vaginal bleeding had increased, but clotting was not now evident. A tentative diagnosis of amniotic fluid embolism and disseminated intravascular coagulation (DIC) was 


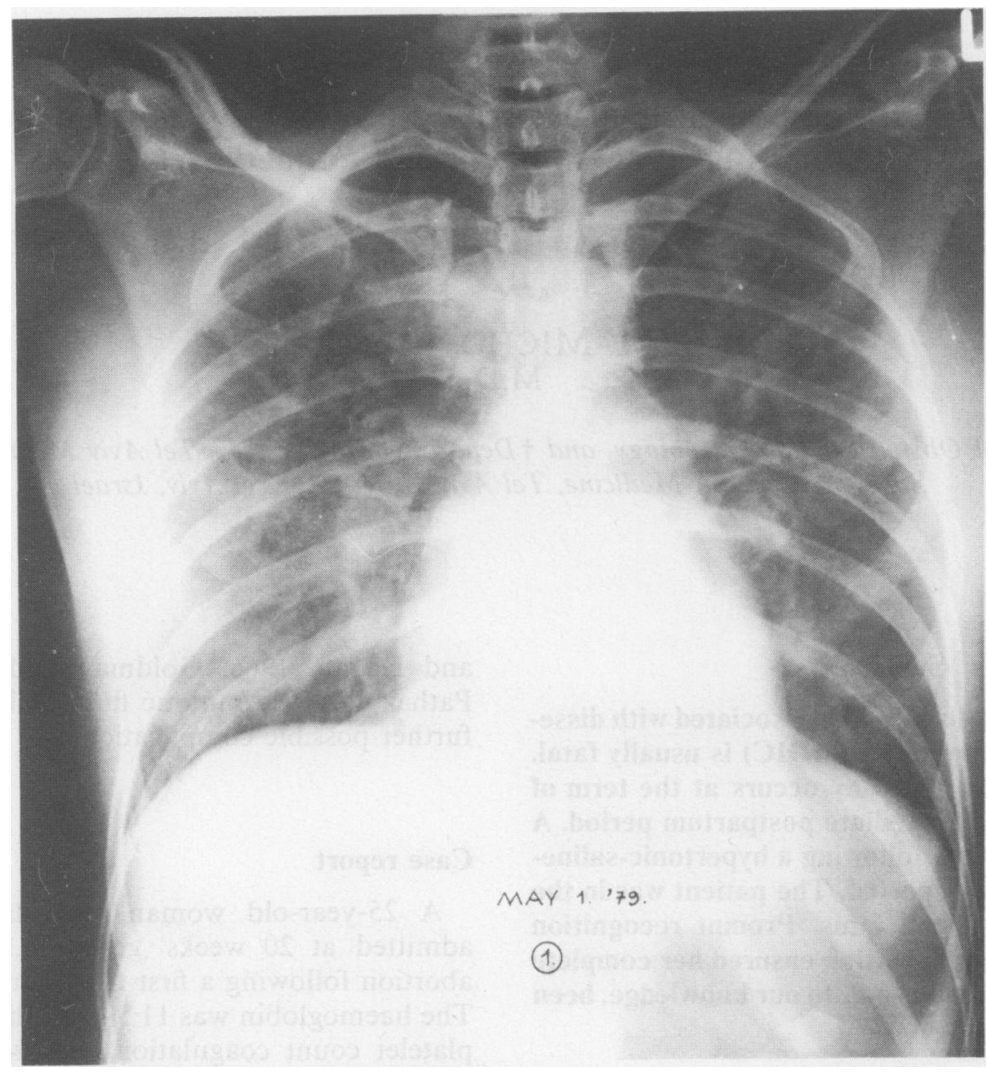

FIG. 1. Chest X-ray $1.5 \mathrm{hr}$ following the onset of respiratory distress showing pulmonary artery engorgement in the hilar region and a $\mathrm{g}$ ne increase in vascular markings over the right lower lung field.

later confirmed by laboratory studies and serial chest $\mathrm{X}$-rays.

ECG shortly after the episode was suggestive of acute right heart strain. Chest $\mathrm{X}$-ray $90 \mathrm{~min}$ after the respiratory distress showed pulmonary artery engorgement at the hilum and finely increased vascular marking in the right lower lung field (Fig. 1). Twelve hours later, a uniform opacity was seen in the right lower lobe in the chest X-ray. Hypoxaemia and hypocarboxaemia supported the diagnosis of acute pulmonary embolism.

Thirty minutes after the apnoeic episode, whole blood clotting time, prothrombin time and partial prothrombin time were all prolonged. Plasma fibrinogen concentration, previously normal, was less than $50 \mathrm{mg} / \mathrm{dl}$. Blood electrolytes were normal at this stage. The patient was given $1000 \mathrm{ml}$ of fresh whole blood to correct blood loss and coagulation defects. One gram of hydrocortisone was given intravenously, and this dose was repeated after $4 \mathrm{hr}$. Intravenous aminophylline $6 \mathrm{mg} / \mathrm{kg}$ was given in $15 \mathrm{~min}$, and a continuous infusion of $0.5 \mathrm{mg} / \mathrm{kg} / \mathrm{hr}$ was then maintained for $4 \mathrm{hr}$. The patient's hypoxaemia wăs treated with intermittent positive pressure respiratiog and $40 \%$ oxygen for $1 \mathrm{hr}$ after the acute episode, when she was extubated. Respiratory support wags continued with an oxygen mask for another $30 \mathrm{hr}$ angd blood gases were checked. The chest X-ray 2 da later showed dramatic clearing of the right lower lobe opacity. The subsequent course was uneventful.

\section{Discussion}

Amniotic fluid embolism is one of the causes of death during labour and in the immediate postpar tum period. It is estimated that there is one death in 20,000-30,000 deliveries (Courtney, 1974; Resnik \& al., 1976). Probably mild episodes of AFE are mofte frequent. AFE should be suspected in all cases of respiratory distress, maternal collapse, coagulation failure or uncontrolled haemorrhage during labout, delivery or postpartum (Courtney, 1974; Reis, Pierç and Behrendt, 1969).

We are not aware of any previous report of AF 
after saline induced abortion involving a live midtrimester fetus and maternal recovery. Since AFE and DIC at term are the sequelae of uterine contractions, with intravasation of amniotic fluid (Sparr and Pritchard, 1958; Wagatsuma, 1965), it is logical that a similar event may occur during saline induced abortion.

Early diagnosis with appropriate and prompt treatment can ensure, as in the present case, pulmonary and cardiovascular resuscitation, with complete recovery.

\section{References}

Abdul-KaRIM, R. \& AsSali, N.S. (1961) Renal function in human pregnancy. V. Effects of oxytocin on renal hemodynamics and water and electrolyte excretion. Journal of Laboratory and Clinical Medicine, 57, 522.

Beller, F.K., Rosenberg, M., Kolker, M. \& Douglas, G.W. (1972) Consumptive coagulopathy associated with intra-amniotic infusion of hypertonic salt. American Journal of Obstetrics and Gynecology, 112, 534.

Brown, F.D., Davidson, E.C. Jr. \& Phillips, L.L. (1972) Coagulation changes after hypertonic saline infusion for late abortion. Obstetrics and Gynecology, 39, 538.

Cameron, J.M. \& DAYAN, A.D. (1966) Association of brain damage with therapeutic abortion induced by amniotic fluid replacement: Report of two cases. British Medical Journal, 1, 1010.

Courtney, L.D. (1974) Amniotic fluid embolism. Obstetrical and Gynecological Survey, 29, 169.

Droegemuller, W. \& GREer, B.E. (1970) Saline versus glucose as a hypertonic solution for abortion. American Journal of Obstetrics and Gynecology, 108, 606.

FrigoletTo, F.D. \& PoKoly, T.B. (1971) Electrolyte dynamics in hypertonic saline-induced abortions. Obstetrics and Gynecology, 38, 647.

Futoran, J.M., Lowenstein, J.M. \& PEACock, W.G. (1969) Experience with intra-amniotic hypertonic saline injections: Aburel's procedure. American Journal of Obstetrics and Gynecology, $105,191$.

GILlmer, M.D.G., Friend, J.R. \& BEARD, R.W. (1971) Termination of pregnancy with intra-amniotic hypertonic saline. British Medical Journal, 1, 434

GoldMAN, J.A. \& ECKERLING, B. (1972) Intracranial dural sinus thrombosis following intrauterine instillation of hypertonic saline. American Journal of Obstetrics and Gynecology, 112, 1132.
GooduIN, R.C. (1971) Complications of amnio-infusion with hypertonic saline for mid-trimester abortion. American Journal of Obstetrics and Gynecology, 110, 885.

Goodlin, R.C., McLennan, C.E., Choyce, J.M., LeE, R.S. \& STICKLER, J.E. (1969) Therapeutic abortion with hypertonic intraamniotic saline. Obstetrics and Gynecology, 34, 1.

halbert, D.R., Buffington, J.S., Crenshaw, C., JR, Brame, R.G. \& SILVER, D. (1972) Consumptive coagulopathy with generalized hemorrhage after hypertonic saline induced abortion. A case report. Obstetrics and Gynecology, 39, 41.

JORGENSEN, J. (1969) Rhesus-antibody development after abortion. Lancet, ii, 1253.

KERENYI, T.D. (1969) Hypernatremia following intrauterine instillation of hypertonic saline solution. Report of a case and discussion. Obstetrics and Gynecology, 33, 520.

KERENYI, T.D. (1971) Out-patient intra-amniotic injection of hypertonic saline. Clinical Obstetrics and Gynecology, 14, 124.

Mackenzie, J.M., Roufa, A. \& Tovell, H.M.M. (1971) Midtrimester abortion: Clinical experience with amniocentesis and hypertonic instillation in $\mathbf{4 0 0}$ patients. Clinical Obstetrics and Gynecology, 14, 107.

Parmley, T.H., Montague, A.C.W. \& Miller, E. (1970) Transplacental hemorrhage in patients subjected to therapeutic abortion. American Journal of Obstetrics and Gynecology, 106, 540.

PATHAK, U.N. (1968) Induction of labor by intra-amniotic injection of saline. American Journal of Obstetrics and Gynecology, 101, 513.

ReIS, R.L., PierCe, W.S. \& BehrendT, D.M. (1969) Hemodynamic effects of amniotic fluid embolism. Surgery, Gynecology and Obstetrics, 129, 45

Resnik, R., Swartz, W.H., Plumer, M.M., Benirschke, K. \& STRATTHAUS, M.E. (1976) Amniotic fluid embolism with survival. Obstetrics and Gynecology, 47, 295.

SPARR, R.A. \& Pritchard, J.A. (1958) Studies to detect the escape of amniotic fluid into the maternal circulation during parturition Surgery, Gynecology and Obstetrics, 107, 560.

STIM, E.M. (1972) Saline abortion, Obstetrics and Gynecology, 40, 247.

SVANE, H. (1960) Interruption of pregnancy by intra-uterine instillation of saline. Danish Medical Bulletin, 7, 51 .

VoIGT, J.C. \& BRITT, R.P. (1969) Foeto-maternal haemorrhage in therapeutic abortion. British Medical Journal, 4, 395.

Wagatsuma, T. (1965) Intra-amniotic injection of saline for therapeutic abortion. American Journal of Obstetrics and Gynecology, 93, 743.

Whalley, P.J. \& Pritchard, J.A. (1963) Oxytoxin and water intoxication. Journal of the American Medical Association, 186, 601.

Wood, C., Booth, R.J. \& Pinkerton, J.H.M. (1962) Induction of labour by intra-amniotic injection of hypertonic saline. British Medical Journal, 2, 706. 